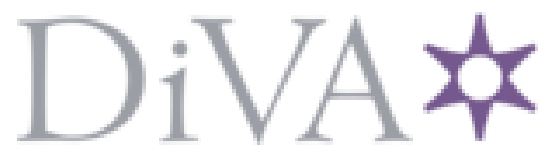

http://www.diva-portal.org

\title{
Postprint
}

This is the accepted version of a paper published in Philosophical Studies. This paper has been peerreviewed but does not include the final publisher proof-corrections or journal pagination.

Citation for the original published paper (version of record):

Glüer-Pagin, K. (2016)

Intentionalism, Defeasibility, and Justification.

Philosophical Studies, 173(4): 1007-1030

https://doi.org/10.1007/s11098-015-0538-6

Access to the published version may require subscription.

N.B. When citing this work, cite the original published paper.

Permanent link to this version:

http://urn.kb.se/resolve?urn=urn:nbn:se:su:diva-137913 


\title{
Forthcoming in a special issue of Phil Studies, ed. by J. Genone, on the epistemology of perception
}

\section{Intentionalism, Defeasibility, and Justification}

\author{
Kathrin Glüer
}

\section{Introduction}

It is hard to deny that perception is a main source of our knowledge of the world around us - provided we have any such knowledge at all. For sentient creatures like us, perceptual experience plays a key role not only in the acquisition, but also in the epistemology and folk-epistemology of our empirical beliefs. Philosophers like to talk of things like "the tribunal of experience", and all of us - if pressed hard enough on why we believe some basic thing about what's in front of our eyes, for instance - will resort to citing their experiences as reasons. "[S] uppose", John McDowell once wrote, reminding us of this, "one asks an ordinary subject why she holds some observational belief, say that an object within her field of view is square. An unsurprising reply might be 'Because it looks that way' " (McDowell 1994, 165).

How to understand and account for the epistemic role of perceptual experience used to be a central topic for philosophers of perception in the empiricist tradition from the 17 th Century onwards. With the decline of empiricism, interest in perception lapsed for a while. Its revival began about 20 years ago. Today, the topic is booming, but so far, most of the hottest debates have taken place within the philosophy of mind. One of the popular views in the philosophy of perception today is intentionalism - the view that perceptual experience is a mental state with sensory phenomenal character and representational content. The nature, kind, and form of this content, its relation to phenomenal character, and even its very existence have been subject to debate for a while now, but intentionalism's potential contribution to, and consequences for, an account of the epistemic role of experience has received less attention so far. ${ }^{1}$ This is changing, however;

\footnotetext{
${ }^{1}$ Notable exceptions are John McDowell (1982; 1994), Bill Brewer (1999), and Tyler Burge(2003). Recently,
} 
interest in the epistemology of perception is growing. There is widespread agreement that to the creatures having them experiences provide some kind of "positive epistemic status" for forming empirical beliefs on their basis. Beyond that, there is little consensus on terminology, and less on substance. Following Jim Pryor (Pryor 2005), I shall use the traditional term "justification" for this positive epistemic status - whatever it precisely amounts to.

For the intentionalist, the question what experiential justification precisely amounts to has a certain shape: The intentionalist is trying to understand, and account for, the epistemic role of experience construed as a conscious mental state with representational content. It might thus seem that the intentionalist is particularly well placed to do justice to both the tribunal metaphors philosophers are fond of - if perception is such a state we can make almost literal sense of the idea that it is making pronouncements - and the folk-epistemological practice of citing these states as providing us with reasons. They are, after all, states that are not only very present in the conscious inner life of their subjects, but according to most, if not all, intentionalists, they represent the world as being a certain way to their subjects. Thus, it is only natural to expect experiential content to play a crucial role in an intentionalist's account of the epistemic role of experience. It is, in other words, only natural for an intentionalist to subscribe to the following "Content Principle" (CP):

(CP) The justificatory role of a perceptual experience is, at least in part, a function of its content.

Given standard versions of intentionalism, however, it is surprisingly difficult to find a plausible account of the epistemic role of experience in which its content actually plays any role. Developing this difficulty in some detail is the aim of this paper. I shall also make a suggestion as to how to get out of it.

I shall proceed as follows: After some terminological remarks, I shall in section 2 spell out what I take to be a very natural picture of experiential justification and why it

Brewer has given up intentionalism completely (cf. Brewer 2006, Brewer 2011), and McDowell has joined Burge in holding that the content of experience is not "propositional" (cf. McDowell 2008). I strongly suspect, though, that the sense(s) in which experiential contents are "non-propositional" according to McDowell and Burge would not disqualify them from being "propositional" in the sense in which I shall use the term. 
gets standard intentionalism into trouble. Standard intentionalism, the worry is, cannot understand the evidential or inferential relations crucial to experiential justification in terms of probabilification without thereby undermining the idea that experiential justification is defeasible. In section 3, the dependence of this "defeasibility problem" on a form of "premise principle" is spelled out. Giving up this principle, and construing experience as what I shall call a mere "justification maker", might be a solution to the defeasibility problem - a rather costly one, however. In section 4, I shall argue that working with propositions about experiences as premises also leads to giving up on the relevant premise principle - and thereby to giving up on (CP). In section 5, I shall have a quick look at the idea that this conclusion can be avoided by means of externalism about the content of experience. And in the final section, I shall briefly outline my own preferred solution to the defeasibility problem.

\section{The defeasibility problem}

Throughout the whole of this paper I shall assume intentionalism. That is, I shall assume that experience does have representational content. ${ }^{2}$ Moreover, I shall assume that intentionalism thereby is committed to construing perceptual experience as a propositional attitude. But the way I use the terminology should actually make this uncontentious. I shall not assume anything about what a proposition is - except that propositions essentially have truth conditions. An intentionalist might prefer to call the correctness conditions of the representational contents of experiences "accuracy" or "satifaction conditions", but the reasons one might have for doing so will not, I think, play any role in what follows. Moreover, in the sense in which I use "truth condition", these all are (varieties of) truth conditions. Correspondingly, I use "propositional attitude" in a wide, uncontentious way: Any mental state that is best construed as a state with propositional content thereby is a propositional attitude. For a mental state, "being a propositional attitude" simply designates the relation of having propositional content. ${ }^{3}$

\footnotetext{
${ }^{2}$ This view has been argued for by quite a number of people in a variety of ways recently, for instance Byrne 2009, Pautz 2009, Siegel 2010, Siegel 2011, Schellenberg 2011, and Glüer 2014. It has been argued against, too, for instance by Martin 2002, Travis 2004, Brewer 2006.

${ }^{3}$ It is, of course, a substantive and extremely interesting question what it precisely takes for a mental state to be a state having propositional content. But that experience qualifies is assumed, not argued for, in this paper. (For my own Davidsonico-Lewisian take on the general question and its answer in the case of experience, see Glüer 2014.)
} 
Intentionalists not only agree that experience has content, there is also some rather widespread agreement amongst intentionalists on what these contents are. Thus, intentionalists tend to agree on the following general formula:

(EC) An experience as of $p$ has the content that $p$.

Moreover, they tend to agree that the objects of perception are ordinary material objects, and that experiences ascribe "sensible properties" such as redness or roundness to such objects. There is disagreement as to the precise form of these contents - disagreement on whether they are singular or general, for instance - and on what exactly the sensible properties are - just properties such as redness and roundness or also properties such as being a book or being a fir tree - but these disagreements will not matter in what follows. For simplicity's sake I shall use a visual experience as of a red book in front of me as my main example, and my standard intentionalist will construe it as having the content that there is a red book in front of me, but I am not thereby excluding intentionalists who think that experiential contents are singular or that properties such as being a book do not get to be elements of such contents from my discussion. Because of the general agreement that experiences basically ascribe ordinary sensible properties to ordinary material objects, I have called the standard intentionalist semantics for experiences a "naive semantics" (cf. Glüer 2009).

When it comes to epistemology, I already said that I shall use "justification" as my term for the positive epistemic status we are interested in. I shall call all the things providing justification "justifiers". ${ }^{4}$ I shall assume that what we are interested in here is restricted to what usually is called "propositional justification", more precisely propositional prima facie justification for (first order) empirical belief. I shall mostly not make

\footnotetext{
Regarding the way the terminology of propositional contents and attitudes is used in this paper, I would like to note that I take it to be basic, widespread, and well-established. As far as I can tell, this is the way in which these terms have mostly been used in the analytic tradition in the philosophy of mind and language. Anyone who thinks that ascribing contents with, for instance, "accuracy conditions" to experiences does not commit them to experiences having propositional contents should tell us what precisely they mean by "proposition" - such that experiential contents are not propositions. Analogously, anyone thinking that construing experiences as having propositional contents does not commit them to their being propositional attitudes owes us an explanation of what, precisely, a propositional attitude is - such that experience isn't one.

${ }^{4}$ Again, this is following Pryor (2005). Pryor, however, uses "justifier" and "justification maker" interchangeably. I shall also make use of "justification maker" later, but I shall use it to designate a subspecies of justifier. I'll explain below.
} 
the prima facie character of the justification explicit in what follows. Further, I am not taking a stand on whether justification in general is to be understood in externalist or internalist terms. I am not committed to the claim that only propositional attitudes, or mental states, provide justification, or the claim that all justification is subject to privileged access conditions. In particular, I am not committed to an internalist construal of the justification relation between experience and experience-based belief (or the evidence relation between their contents), nor am I committed to any claims concerning the ability of the experiencing subject to think of their evidence as evidence.

What we are interested in here is the epistemic relation between perceptual experience and (first order) empirical belief, in particular, the relation between perceptual experience and what I shall call "basic perceptual belief", i.e. the epistemically most basic kind of belief that can be formed on the basis of experience. I shall now develop the basic outlines of what I take to be, for the intentionalist, a natural picture of this relation. This is not to say that this is the only possible picture, nor that there aren't other, quite possibly very useful ways of construing epistemic relations between experience and empirical belief. The claim is only that the following is a natural way of thinking worth trying to accommodate. Being able to accommodate it would be a theoretical virtue for any account of experience, but especially for the intentionalist's.

Imagine a subject $S$ having an experience as of a red book in front of her. She forms the belief that there is a red book in front of her on the basis of that experience. Under certain circumstances, that belief - if formed "in the right way" - will be (doxastically) justified. And under those circumstances, $S$ would have what is usually called propositional justification for forming a belief with that content even if, for some reason, she didn't do so. Either way, it is natural to think that the experience has something to do with the justification $S$ has for the belief. It is natural to think of the experience as a justifier, that is. The experience might not be the sole factor responsible for $S$ 's having this justification, but intuitively, it seems very plausible that it makes a significant contribution to it. The following "principle of experiential justification providing" (EJ) is thus plausible:

(EJ) Perceptual experience provides justification for basic perceptual belief.

Now, imagine our subject having another red book experience just like the first one, 
but this time, she knows that the relevant book in fact is white and that it's looking red is caused by very clever red lighting. Under these circumstances, basing a belief that there is a red book in front of her on her experience is not justified. But the experience is just as much an experience as of a red book as the first experience is - let's assume that these two experiences are subjectively indistinguishable for $S$. It is then natural to think that their inherent "justifying powers" are no different, either. ${ }^{5}$ It is just that these powers are "overpowered" by background belief in the second case. It is thus very natural to think that experiential justification is defeasible. What experience provides, is prima facie justification, justification that can be defeated - for instance, by (justified) background belief, or knowledge, to the effect that circumstances are such that experience cannot be "trusted". Perceptual knowledge is the very paradigm of fallible knowledge or justified belief: knowledge (or justified belief) based on evidence that is sufficiently strong, but nevertheless compatible with the justified belief's falsity. ${ }^{6}$

The experience as of a red book thus provides prima facie justification for a red book belief in either of our cases. The difference is that in the second case this prima facie justification is defeated, while in the first case it wins the day. Experiential justification thus obeys what we might call "the defeasibility principle" (DP):

\footnotetext{
${ }^{5}$ Again, all I am doing is spelling out a "natural" train of thought. Epistemic disjunctivists (such as McDowell) would deny that these two perceptual states are epistemically equipowerful. But that is, of course, compatible with its being natural or intuitive to think that they are. And, prima facie at least, intentionalists seem in a good position to develop an account that allows us to think of the epistemic role of experience along the lines just described as natural or intuitive. Schellenberg acknowledges this but nevertheless thinks that subjectively indistinguishable veridical and illusory experiences do not share all their epistemic powers; according to her, illusions provide "phenomenal evidence", but veridical experiences provide both "phenomenal" and "factive evidence" (Schellenberg 2013).

${ }^{6}$ Not everyone agrees. Comesaña urges us not to "confuse" defeasibility with non-entailment. According to him, the basic notion of defeasible justification is that of "justification which can be lost given improvements in one's epistemic position” (Comesaña 2014, 232 (paraphrasing Pryor 2000, 517)). He provides the following example to show that what he calls "entailing justification" is defeasible: "Suppose (...) you have a proof of some complicated theorem. You then show it to a very competent mathematician and (mistakenly) he assures you that there is a fallacy in the proof. You then cease to be justified in believing the theorem, even though you did have (and perhaps still have) evidence which entails it" (Comesaña 2014, 232).

I am not sure in what sense this example involves any "improvements in one's epistemic situation", and I am not sure that, intuitively, justification is lost in this case. But in any case, the notion of defeat exemplified here would seem rather different from the "fallibilist" notion I am using. As illustrated in the example, Comesaña's notion of defeat does not seem to restrict defeat to being defeated by good reasons or defeaters. Of course, a subject can lose a belief for all sorts of reasons (or none), but not all of these cases are cases in which the justification for that belief is actually defeated (in the fallibilist sense). Moreover, the example involves complicated entailment by logical (or mathematical) truth, and such cases are special, and vexed, in a variety of ways that make generalizing from them less than safe. More on entailment and the defeasibility of experiential justification in section 3 .
} 
Taken together with our assumption of intentionalism, this strongly suggests that a certain, widely accepted basic way of thinking of defeasible justificatory relations between propositional attitudes is applicable here. On this model, the relevant propositional attitudes are construed as providing their subject with justification for forming beliefs in virtue of their contents standing in evidential relations to the contents of the beliefs they provide the justification for. For empirical beliefs, these evidential relations are construed as relations of probabilification. Strictly speaking, these relations hold between propositions: the content of the justifier and the content of the belief it provides justification for. If the content $p$ of the justifier is true, then the content of the justified belief $q$ is more likely to be true than it was on its own, so to speak (the conditional probability of $q$ on $p$ is higher than the prior probability of $q) .^{7,8}$ This model seems applicable here because we are interested in justification for empirical belief, justification that moreover is provided by a justifier that itself has propositional content. But on top of that, the model particularly recommends itself because the justification we are dealing with is defeasible in the way described. Such defeasibility, it would seem, requires justificatory relations that come in degrees of strength, relations whose presence leaves room for the falsity of the justified belief. Relations of probabilification would seem to fit that bill rather well.

This further suggests understanding rational belief formation on the basis of perceptual evidence by means of an "update model": experience provides a subject with new information, and this makes it (prima facie) rational to update one's credences in the light of the incoming information. In what follows I shall often refer to the incoming information to be updated upon as the "input proposition". Moreover, it seems natural to think of updating on an experiential input proposition in broadly Bayesian terms: as

\footnotetext{
${ }^{7}$ The relations between the contents we are trying to capture here are usually called "inferential" or "evidential relations". This is a concept of evidence that applies to propositions only. Williamson (2000, 194ff) makes a quite persuasive case for the claim that all evidence is propositional. The truth of that claim, however, is not presupposed here. What makes a propositional concept of evidence natural to turn to in our context is that we work from the assumption that the justifier we are interested in has propositional content.

${ }^{8}$ Among other things in order to allow for evidence to remain evidence even after having been updated upon, we should only require that the conditional probability of $q$ on $p$ is not lower than the prior probability of $p$. I shall abstract from problems like this here.
} 
updating in accordance with the prior conditional probabilities assigned to the truth of various propositions on the input proposition. ${ }^{9}$

The idea of thinking of perceptual evidence in probabilistic terms suggests itself from a slightly different pre-theoretic angle as well. Having a visual experience as of a red book in front of me usually is a pretty good indicator of there being one. Having such an experience makes it quite likely that there really is a red book where it seems to be. Quite likely, but not certain - appearances after all are known for their ability to deceive. An experience as of a red book, then, is a good, but not infallible, indicator of there being such a book: it's "reliable", but not totally so. Again, the basic upshot is that experience provides justification for believing that $p$ by making the truth of $p$ (more) probable.

The next question, then, is how, precisely, experience does that. And it is here that the idea we started out with finally kicks in: for an intentionalist, it would seem, the explanation at this point should turn on the content of the experience. Thinking along such lines, Alvin Goldman has recently suggested an account of experiential justification that combines reliabilist elements with evidentialist elements. In developing this "hybrid account", Goldman advocates unpacking the evidentialist notion of justified belief's "fitting one's evidence" in precisely probabilistic terms:

In the case of inferential fittingness, we proposed that the relevant relation is that the truth of the contents of the premises should make probable the truth of the content of the conclusion. Perhaps the same idea can work here. Perhaps we can say that a belief in proposition $p$ fits the evidence provided by experiential state $E$ just in case the truth of the content of $E$ makes (highly) probable the truth of $p$ (Goldman 2011, 273).

This is very much on the right track, it seems to me. The input proposition provided by

\footnotetext{
${ }^{9}$ Such a model is, for instance, used by at least some of the contributors to the recent discussion about the potential anti-skeptical punch of "dogmatism" about experiential justification. "The dogmatist about perceptual justification says that when it perceptually seems to you as if $p$ is the case, you have a kind of justification for believing $p$ that does not presuppose or rest on your justification for anything else, which could be cited in an argument (even an ampliative argument) for $p$. To have this justification for believing $p$, you need only have an experience that represents $p$ as being the case. No further awareness or reflection or background beliefs are required. Of course, other beliefs you have might defeat or undermine this justification. But no other beliefs are required for it to be in place" (Pryor 2000, 519). Contributors to that discussion include Wright 2004, Wright 2007, Cohen 2005, White 2006, McGrath 2013. Silins 2014 investigates in more detail how to think of defeaters of experiential justification in precisely such a model. See also below, fn. 19.
} 
an experience, the information to be updated upon, is most naturally taken to be the experience's content. This would give us (PC):

(PC) An experience provides justification for believing that $p$ only if the truth of the experience's content makes the truth of $p$ (more) probable.

But now, we have gotten ourselves into trouble. We do indeed want input propositions that can make it highly probable that $p$ - but we do not want propositions that make it "too probable". The trouble is that we seem to have gotten input propositions that precisely do the latter. The worry thus is that standard intentionalism cannot embrace (PC) and (DP), the principle of defeasibility, at the same time.

As we said earlier, defeasible justification for $p$ needs to leave room for $p$ 's being false. Therefore, thinking of experiential justification for believing $p$ in probabilistic terms requires not only that the probability of $p$ be raised - it also requires that it not be raised too much. Experiential justification for believing $p$, in other words, must not be such that the probability of $p$ on the truth of the experience's content is 1 . If it is, defeasibility is lost. ${ }^{10}$ Combining these considerations would give us the following principle for defeasible experiential justification:

(DPC) An experience with content $e$ provides defeasible justification for believing that $p$ only if $1>\operatorname{Pr}(p \mid e) \geq \operatorname{Pr}(p)$.

It is now easy to see the problem standard intentionalism has with (DPC). According to standard intentionalism the content of an experience as of $p$ is $-p$. For instance, the content of an experience as of a red book in front of me is that there is a red book in front of me. And the basic perceptual belief this experience is supposed to provide defeasible, prima facie justification for is the belief that there is a red book in front of me. According

\footnotetext{
${ }^{10}$ The point here does not depend on using an update model assigning probability 1 to incoming information. It is sometimes suggested that we could get around this problem by using Jeffrey conditionalization (I haven't seen this suggestion spelt out anywhere, though). There would seem to be at least two problems with it. First, it is not clear how to even apply Jeffrey conditionalization in our case - Jeffrey conditionalization is designed for updating on experience on the assumption that experience does not have propositional content. The basic idea behind such suggestions might be to assign a probability less than 1 to the incoming experiential proposition, but even then, we would still need to update perceptual belief in $p$ on this basis, i.e. we would still be stuck with updating $p$ on $p$. This would never result in assigning $p$ a lower probability than the one it came in with. But, second, it is precisely the possibility of such lowering which is required in the step from experience to belief. As long a you go from $p$ to $p$, it would never seem rational to lower you credence in the process. (Thanks to Susanna Schellenberg for discussion here.)
} 
to standard intentionalism, we form basic perceptual beliefs by "taking our experience at face value" in the sense of coming to believe "what they tell us": their content.

But isn't it only on a rather simplistic version of intentionalism that this problem arises? I don't think so. Let's consider this in some more detail. On the simplest version of intentionalism, the relation between the experience content and the content of the basic perceptual belief it justifies indeed is that of identity. In that case, it is clear that the conditional probability of belief content on experience content is 1 . But of course, many intentionalists think that experience content is not strictly speaking identical to belief content. Experience content, it is often said, is necessarily both much "richer" and much more "fine-grained" than the content of any belief we can base on experience. It is richer in containing much more information, and more fine-grained in the sense of being much more determinate. A plausible way of thinking of richness and fineness of grain would seem to be in terms of long conjunctions of very determinate properties. If that is correct, the relevant inferences from experience content to belief content would nevertheless not result in probabilities lower than 1. On the assumption that they proceed via conjunction elimination and from determinates to determinables, it should be clear that they cannot result in probability lowering. The conditional probability of $p$ on $p$ and $q$ is 1 , and so is the conditional probability of $o$ is red on $o$ is red ra $_{52}$.

Some intentionalists also, quite plausibly, think that the processing step from experience to belief involves a change in the medium of representation. Plausible as that it is, what it would amount to is a sort of "translation", a translation that might well be responsible for the sort of loss of information or determinateness we just considered. But probabilities don't change with the medium of representation, and even if something is lost in translation here, what isn't lost would presumably be such that its conditional probability on the original content is 1 .

Some intentionalists think that experience and belief not only employ different media of representation - they also take different kinds of content. Experience content, it is often said, is non-conceptual content, while belief content is conceptual. The step from experience to belief might then be described as one of "conceptualization". The distinction between conceptual and non-conceptual content is notoriously difficult to pin down (for discussion, see Heck 2000; 2007, Speaks 2005), but it is hard to see how it 
might help here.

If the difference is a difference in the subject's relation to one and the same content, conceptualization clearly would not affect conditional probability. If the difference is one in the kind of content experiences and belief have, however, things are quite a bit more complicated. Could we, for instance, get the desired effect if we thought of experience content as Russellian, and belief content as Fregean? It's a good question, but I am inclined to think not. Probabilities, it would seem, go with truth conditions. But then, it would be plausible to think that they initially get distributed over a basic possibility space, i.e. a space of possible worlds, and thus assigned to possible worlds propositions. From them, they get inherited, so to speak, by every finer-grained proposition that determines the same truth condition. If that is a good way to think about these matters, a Russellian proposition $R$ and a Fregean proposition $F$ that determine the same truth condition as a possible worlds proposition $p$ will both have the same probability as $p$. So, if we were to think of an experience as having, for instance, a Russellian content involving an object $o$ and a property $P$, while the basic perceptual belief justified by such an experience would have a Fregean content involving a mode of presentation of $o$ and a mode of presentation of $P$, the conditional probability of the latter on the former should still be $1 .{ }^{11}$ I am thus inclined to think that standard intentionalism indeed is in trouble. On the assumption that experience has a standard "naive" semantics, (EJ), (DP), and (DPC) form an inconsistent triad. Let's call this "the defeasibility problem". As noted, the defeasibility problem is a problem for standard intentionalism about experience. ${ }^{12,13}$

\footnotetext{
${ }^{11}$ Even if you find this plausible for objective probabilities, you might think that Fregean contents should be assigned subjective probabilities instead. After all, using them would seem to be motivated by wanting to account for a subjective perspective on the world. I agree, but I am not sure how that would help here. How would "going subjective on Fregean probabilities" justify a subject in lowering their credence when going from experience to belief? Of course, a subject might (wrongly) think that the region of possibility space corresponding to a "Russellian property" is, in fact, occupied by several non-identical properties, properties the subject not only thinks of under different modes of presentation, but also takes to be non-identical. There might be nothing subjectively irrational about this, but nevertheless, it would seem as if any rational assignment of a probability lower than that of the initial Russellian proposition would require an "objective" mistake on the subject's part. A subject not mistaken about the identity of the relevant properties cannot rationally lower their probability when making such a transition. This does not seem the right model on which to think of defeasibility. Defeasibility should not be such that it requires mistake.

${ }^{12}$ Should it turn out to be possible to deal with the defeasibility problem by means of construing the step from experience to belief as some kind of "Fregeanization" of the experience content, that would by itself be a very interesting result constraining plausible versions of intentionalism.

${ }^{13}$ The defeasibility problem is, of course, related to what I have called the "stuttering inference argument" elsewhere. This is the argument that if experience provides its subject with inferential reasons for basic
} 


\section{Premise Principles}

In his 2005 paper “There is Immediate Justification”, Jim Pryor formulates a principle he calls the "Premise Principle":

(PP) "The only things that can justify a belief that $\mathrm{P}$ are other states that assertively represent propositions, and those propositions have to be ones that could be used as premises in an argument for P. They have to stand in some kind of inferential relation to $\mathrm{P}$ : they have to imply it or inductively support it or something like that" (Pryor 2005, 189).

Pryor ultimately argues against (PP) and for the conclusion that there are justifiers that are not "states that assertively represent propositions". I shall not take any stand on that here. Maybe there are such justifiers. But I take it that experiences, as conceived of by the intentionalist, won't be among them. After all, intentionalists usually agree that experiences not just have propositional contents, but that they represent the world as being a certain way, i.e. such that those contents are true. It is something like this that Pryor has in mind when speaking of "assertively representing". 14 But the premise principle puts a second condition on justifiers: Their contents have to stand in an inferential relation to that of the beliefs they provide justification for. I shall call justifiers satisfying both conditions "inferential justifiers". That a justifier "assertively representing a proposition" would indeed justify by providing inferential or evidential support would seem a rather natural idea. But assume that there are justifiers that don't have any content. Mere sensations might be candidates; according to Pryor, my headache is a justifier for the introspective belief that I have a headache. I shall not discuss this claim here, either. Let's simply grant for a moment that there are justifiers without any content, and that the main candidates might well be right here among our mental states. We might then

perceptual belief, standard intentionalism will have to construe the relevant inference as a "stuttering inference": an inference from $p$ to $p$ (cf. Glüer 2009). The argument is due to McDowell (cf. McDowell 1998, 405f). McDowell uses it as an argument against the claim that experience provides inferential reasons for basic perceptual beliefs, while I have used it as an argument against construing experience content as naive.

${ }^{14}$ Others have used different terminology for essentially the same idea: There is widespread agreement that experiences not only have propositional content, they also have what Searle calls "mind-to-world direction of fit" (cf. Searle 1983, 7ff) and "aim at truth" (Crane 2001, 150). They are thus "assertive" (Heck 2000, 509), "committal" (Burge 2003, 452), or "stative" (Martin 2002, 386f) states. I have argued that experiences not only are like belief in these respects, but in fact are a (special) kind of belief (Glüer 2009). 
ask whether there couldn't be states with content, too, that do not justify by means of an inferential relation between their content and that of the relevant belief. Rather, they would provide justification in some other way - for instance, the way a headache does. We might ask, in other words, whether the following restricted version of the premise principle holds:

$\left(\mathrm{PP}_{2}\right) \quad$ A state that assertively represents a proposition $e$ only justifies a belief that $p$ if $e$ could be used as a premise in an argument for $p$. $e$ has to stand in some kind of inferential relation to $p$ : $e$ has to imply it or inductively support it or something like that.

I shall call all putative justifiers that do not justify by providing inferential support "justification makers". I am not ruling out that there are justification makers. I am not even ruling out that there are justification makers that assertively represent propositions. Denying $\left(\mathrm{PP}_{2}\right)$ and conceiving of experiences as mere justification makers would certainly be an option the intentionalist could consider in order to deal with the defeasibility problem. It would amount to construing experiences, in a certain sense, as contentful inner states providing only a kind of "externalist" justification. And it should be a bit of a last resort, it seems to me. Not only would it get us pretty much back to square one in terms of explaining how experience provides justification. It would also make it difficult to understand just what we are doing when we cite out experiences as reasons for our beliefs. When pressed on why I bought a particularly ugly orange notebook, I can give a perfectly acceptable folk-psychological explanation of that action in terms of the way the notebook looked to me in the shop - namely beautifully dark red - thereby simultaneously providing a perfectly acceptable reason as to why I formed the belief that indeed, the notebook was dark red. This is intuitively very different from being pressed on why I believe that I have a headache. Even if I were to politely answer such a query by saying that I feel it, what I thereby do is basically just pointing out that we are talking about an object of a sensory nature, an object to which I have some sort of special access. Intuitively, that is not at all what we are doing when citing experiences to justify or explain empirical beliefs. Here, we are citing things that look decidedly contentlike: the objects of the experience - as opposed to the experience as an object - and the properties we ex- 
perienced them as having. ${ }^{15}$ It would thus be preferable to be able to account for both at the same time: Our practice of citing experiences as reasons and their actual justificatory powers. Moreover, should we ultimately come to the conclusion that this can't be done, we ought to be able to explain what it is that makes experiences so different from other states "assertively representing propositions", most notably what it is about experiences that makes them so different from beliefs. So different, that is, that they do "assertively represent propositions" but their doing so becomes irrelevant for the epistemology of belief based on it.

Before we deny $\left(\mathrm{PP}_{2}\right)$, we therefore should look around for simpler solutions to the defeasibility problem. The simplest might be to settle for the idea that experiential justification "stutters": Couldn't we just accept that the inference from the content of an experience to that of a basic perceptual belief justified by it goes from $p$ to $p$ ? Can't we just delete ' 1 >' from (DPC) and embrace $\left(\mathrm{DPC}^{\prime}\right)$ ?

(DPC $)$ An experience with content $e$ provides defeasible justification for believing that $p$ only if $\operatorname{Pr}(p \mid e) \geq \operatorname{Pr}(p)$.

The problem with that, it seems to me, is that the resulting principle is false. We can accept that there is an "inference" from $p$ to $p$, and even that $p$ provides evidential support for $p .{ }^{16}$ That is not the problem. The problem is precisely defeasibility. As long as the probability of $p$ given that $p$ is 1 , updating on $p$ does not leave any room for the possibility that not- $p$. To leave room for a defeater to even engage with it, the connection between $e$, the content of the experience, and $p$, the content of the belief, must be such that it allows for there being conditions under which e is true, but $p$ is not. This does not depend on the kind of defeater we are considering. Whether it is of the "rebutting" or of the "undermining" kind, no defeater can "get at" the connection between $p$ and $p .{ }^{17}$ It

\footnotetext{
${ }^{15}$ Even if we think that both examples are paradigmatic examples of "immediate justification", it is not clear to me why that would mean that we should prefer a uniform treatment of these states' justificatory role (cf. Pryor 2005, Siegel and Silins forthcoming for discussion). At least as long as we are intentionalists holding that experiences do, but mere sensations do not, have representational contents, it seems to me that this difference between the putative justifiers would be quite sufficient to expect and motivate differences in the account of precisely how they provide justification. As Pryor notes, justification can be immediate even if the justifier has content and obeys $\left(\mathrm{PP}_{2}\right)$ (cf. Pryor 2005, 191). See also below, note 22.

${ }^{16}$ Cf. Williamson 2000, 187f. on that.

${ }^{17}$ This should be rather clear for "underminers", i.e. defeaters attacking the connection between premise $e$ and conclusion $p$. To be underminable, this connection must be such that there are conditions under
} 
is precisely the presence of ' $1>$ ' that makes (DPC) into a principle an update model of defeasible experiential justification has to obey. ${ }^{18}$

which $e$ is true but $p$ is not. Considered as a whole, the relevant possibility space is such that at most of its " $e$-points" (points where $e$ holds), $p$ holds, too. But there also are true subsets of the $e$-points for which it is not the case that at most of them $p$ also holds. For instance, on the whole, an experience as of a red book in front of you is such that it makes it very likely that there in fact is one, but under conditions of red lighting, this is not the case.

One might think that it does not hold for "rebutters", i.e. defeaters that attack the conclusion directly. Thus, you might have an experience that "tells you" one thing - there is a red book in front of you - but at the same time, an expert tells you that there is no such book. But that would be a mistake. To be able to "rebut" the information from experience, the defeater even in this case needs to be able to engage with it. As long as what you have is nothing but outrightly contradictory incoming information, there is nothing you can rationally do with that. It's simply not possible to update on both $p$ and not- $p$ at once. What you can update on is the conjunction of experience tells me that $p$ and this expert tells me that not- $p$. But then, we have precisely switched to a premise (experience tells me that $p$ ) which is compatible with the falseness of $p$.

${ }^{18}$ In his very helpful comments on a prior version of this paper, Juan Comesaña suggests that there is a different way of denying (DPC) while holding on to all the other principles listed above. As we saw above (fn. 6), Comesaña uses a different notion of defeasibility according to which justification in general remains defeasible even if the content of the justifier entails that of the justified belief (cf. Comesaña 2014, 232). In his comments, he suggests adapting the framework suggested by Williamson (Williamson 2000, 209ff) to help model the defeasibility of entailing justification. This, he suggests, does not require the Williamsonian equation of evidence with knowledge, nor even the assumption that all evidence is true. All we need is the existence of one true epistemic probability function $\mathrm{C}$ and the possibility of striking propositions from the evidence a subject $S$ has at a time $t$. The credences it is rational for $S$ to have in a proposition $p$ then result from conditionalizing $C$ on the evidence $S$ has at $t$. Suppose at $t_{1}$, S's evidence contains $q$ and $p$ is entailed by $q$. At $t_{1}$, S then has justification for believing $p$, and the probability of $p$ on $q$ is 1 . Nevertheless, it is perfectly possible that at a later time $t_{2}$, S has lost this justification for believing $p$-because $q$ is no longer part of $S$ 's evidence. Thus, justification can be lost by loss of evidence. Williamson's paradigm example for such loss is forgetting what one once knew. Let's call this a "defeat by loss" model.

Comesaña suggests that this model can be quite straightforwardly applied to experiential justification. Suppose that at $t_{1}$, I have an experience with the content that there is a red book in front of me, and no defeating evidence. At $t_{1}$, the proposition that there is a red book in front of me is part of my evidence. But at $t_{2}$, I learn that there are red lights shining on the book. At $t_{2}$, Comesaña claims, the proposition that there is a red book in front of me is no longer part of my evidence, and my credence in it should therefore be considerably lower than at $t_{1}$.

Even if we consider the defeat by loss model as simply a model employing an alternative notion of defeat, it doesn't seem to fit justificatory relations between experience and belief particularly well. Here are two reasons for thinking that it won't provide a satisfactory account of such relations: First, defeat here amounts to saying that my experience does not provide me with evidence or justification at $t_{2}$. And that just does not seem right - we must not forget that we have been talking about prima facie justification all along. At $t_{2}$, I have lost my (all things considered) justification for believing that there is a red book in front of me, but not because my experience has stopped providing me with prima facie justification for that belief. Rather, it is because the prima facie justification it provides at both $t_{1}$ and $t_{2}$ has been overridden at $t_{2}$. At $t_{2}$, when both the experience and the belief that the lighting on the book is red have to be taken into account when determining my overall (or all things considered) justification for believing that there is a red book in front of me, the result is no longer strong enough for outright belief. Having one's experience overridden, whether by background belief or by a newly acquired belief, is not like forgetting one's evidence.

That even defeated experience continues to provide you with prima facie justification can also be seen from considerations like the following: even at $t_{2}$, the experience as of a red book in front of me raises the probability of there being a red book in front of me (compared to the probability that proposition has all on its own). That is, even together with the (justified) belief that there are red lights shining on the book, the experience provides prima facie justification for believing that there is a red book in front of me. It's just that 
Thus, it seems to me, the easiest way out of the defeasibility problem is blocked. We have to do something a bit more radical. As we have just seen, we need an input proposition $e$ the truth of which is compatible with the falsity of the proposition $p$ it inferentially supports. Read like this, what the defeasibility problem teaches us is that we only can understand fallible experiential justification in probabilistic terms if the input proposition $e$ is suitably different from $p$. I shall call this the "difference requirement": defeasibility requires difference.

\section{Different Premises}

There are different ways of achieving difference, and they come at different costs. If we want to keep all other principles intact, we can modify our intentionalism, i.e. give up on (EC):

(EC) An experience as of $p$ has the content that $p$.

I think this is by far the best way of providing the difference that defeasibility requires. I suggest construing (visual) experiences as having what I have called "phenomenal contents", contents like $x$ looks $F$ or it looks to to me as if p (cf. Glüer 2009; Glüer 2012b; Glüer 2014). It is possible that Goldman's suggestion is meant to work with a difference in experiential content, too. He is, after all, very explicit about it's being the content of the experience that makes the truth of $p$ "(highly) probable" (Goldman 2011, 273). Goldman goes on to illustrate the idea for visual shape perception, using a proposal popular among vision scientists according to which "the visual system represent object shapes in terms of parts constructed out of geometrical 'ions' (elements), called geons" (Goldman 2011, 274). He explains:

now, it provides equally strong prima facie justification for believing that there is a white book in front of me. (Further knowledge about the surrounding conditions might tip the balance in one or the other direction.) A defeat by loss model on which all we can do is, so to speak, switch experience's evidential powers either on or off won't be able to account for this.

Secondly, on Comesaña's defeat by loss model it remains mysterious just why it would be rational for me to switch the experience off at $t_{2}$. The model does not provide any explanation of the defeat itself; it is only concerned with what happens (or should happen) afterwards. But what we wanted to know was why the experience is "switched off" at $t_{2}$, so to speak, not what it is rational to believe once it has been switched off. (On Williamson's own model, we do get an externalist explanation here: Evidence gets switched off when it is no longer known, but, as I said, Comesaña does not think the plausibility of his idea depends on the Williamsonian equation of evidence with knowledge.) 
Assume now that geonic combinations are a type of (high-level) visual representation, and that, in normal circumstances, a specific geonic combination $\mathrm{G}$ is tokened only when a giraffe is present. Then the truth of a G-token's content makes it highly probable that the proposition 'A giraffe is in the vicinity' is true. Hence, it is fitting for a subject to believe the latter proposition when a G-representation is tokened (ibid.).

But Goldman does not tell us what the content of the G-token is. Nor does he tell us whether the giraffe-proposition in his example is meant to be the content of the most basic perceptual belief to be based on the G-experience. Thus, it remains unclear whether Goldman will ultimately be able to avoid the conclusion that the conditional probability of the relevant most basic perceptual belief on the content of the G-token is 1 .

What Goldman, very plausibly, reasons from, however, is that G-tokening makes giraffe presence highly likely. Since experiences are good indicators of environmental conditions, it is the very occurrence of the experience that makes it likely that there is a giraffe nearby. This supplies another idea of how to achieve difference: A proposition about the experience could be used as input. And in fact, this is at least sometimes simply assumed in the relevant discussions. Thus, when discussing "Problems for Dogmatism" (2006), Roger White uses an "appearance proposition" like $\left(\mathrm{H}_{1}\right)$ as input proposition:

$\left(\mathrm{H}_{1}\right) \quad$ It appears to me that his is a hand.

(White 2006, 528).

White then spells out how the truth of $\left(\mathrm{H}_{1}\right)$ indeed raises the probability of $\left(\mathrm{H}_{2}\right)$ :

$\left(\mathrm{H}_{2}\right)$ This is a hand,

and thus can be seen as providing justification for believing $\left(\mathrm{H}_{2}\right)$ on an update model (cf. White 2006, 531ff). ${ }^{19}$ Similarly, when defending the $\mathrm{E}=\mathrm{K}$ claim - i.e. the claim

\footnotetext{
${ }^{19}$ The "problem for dogmatism" here is just that $\left(\mathrm{H}_{1}\right)$ also raises the probability of $\left(\mathrm{H}_{3}\right)$ :

$\left(\mathrm{H}_{3}\right) \quad$ This is a fake-hand.
}

Thus, it does not look as if experience provides the kind of anti-skeptical punch that dogmatism advertises: Rather than boosting justification for rejecting what we might call phenomenally equivalent skeptical hypotheses, experience seems to do the opposite (cf. White 2006, 531ff. There is work in progress by Jim Pryor in reaction to this (accessible on his homepage). See also Cohen 2005, Wright 2004, Wright 2007, Spectre 2009, McGrath 2013 for relevant discussion. The basic observation goes back to Carnap (1950). The phenomenon is also noted (but welcomed) in Glüer 2014. 
that it is our knowledge, and only our knowledge, that is our evidence - Tim Williamson rescues the intuitive idea that even illusions and hallucinations provide their subject with evidence by maintaining that the propositions known by the subjects of illusions and hallucinations are appearance propositions:

In unfavourable circumstances, one fails to gain perceptual knowledge, perhaps because things are not the way they appear to be. One does not know that things are that way, and $\mathrm{E}=\mathrm{K}$ excludes the proposition that they are as evidence. Nevertheless, one still has perceptual evidence, even if the propositions it supports are false. True propositions can make false propositions probable, as when someone is skilfully framed for a crime of which she is innocent. If perceptual evidence in the case of illusions consists of true propositions, what are they? The obvious answer is: the proposition that things appear that way (Williamson 2000, 198, emphasis added).

But taking the relevant input propositions to be propositions about experiences raises a serious worry for our account of experiential justification. As Schellenberg puts it: "the Williamsonian view requires positing that we do not get evidence directly through our experience when we hallucinate, but only through introspection. Arguably, however, experience provides us with evidence directly - even when we hallucinate" (Schellenberg 2013, 738).

Using propositions about experience to achieve difference is, of course, to give up on both (DPC) and (PC). In a way, Schellenberg just spells out the consequences of that move for this particular kind of input proposition. If we give up on the idea that the input proposition is the content of the experience, but hold on to the idea that what provides that proposition is an inferential justifier, this justifier cannot be the experience, either. Thus, the experience is no longer the most immediate or "direct" justifier for basic perceptual belief. And if our candidate inputs are propositions about our own current experiences, their prime "source" would be introspection. ${ }^{20}$

\footnotetext{
${ }^{20}$ In order to satisfy the difference requirement in full generality, the move to appearance propositions cannot be limited to cases of illusion or hallucination, either. To use this move to diffuse the defeasibility problem, we have to apply it across the board. All justification for basic perceptual belief would come via introspection, then.
} 
Moreover, if we use propositions about experience as inputs, the experiences would simply not play any role as inferential justifiers - not even an "indirect" one. To be sure, their presence would be required for the introspective belief's truth. Just as the presence of a headache (of mine) is required for the truth of the introspective belief that I have a headache. Or as the presence of a hand is required for the truth of my belief that this is a hand. This relation does not require the object of the belief to have any content. And even if it has one, no cheques are drawn on its truth. If the object of an introspective belief has a content, its truth value is irrelevant not only for the truth, but also for the justificatory powers of the belief: The truth of $p$ is not required for the introspective belief that it appears to me that $p$ to provide justification for the belief that $p$. That is precisely why appearance propositions were a candidate for being "suitably different" input propositions in the first place. ${ }^{21}$ Giving up on (DPC) and (PC) to achieve difference by means of using propositions about experience as input propositions thus excludes experiences from being inferential justifiers at all. ${ }^{22}$ On this proposal, it looks as if the content of experience plays no epistemic role whatsoever - neither directly for the justification of basic perceptual belief, nor indirectly, via the justification of introspective belief about experience. Thus, we seem to be driven to give up on the Content Principle itself:

(CP) The justificatory role of a perceptual experience is, at least in part, a function of

\footnotetext{
${ }^{21}$ But don't "first order" mental states such as beliefs provide justification for introspective "second order" beliefs? Possibly. But if so, they do not do so by means of providing inferential support. They would be mere justification makers. And of course, experience might then be a mere justification maker for introspective beliefs, too. All I am saying right now is that that does not make experience into an inferential justifier, not even an indirect one.

${ }^{22}$ On the assumption that beliefs do justify beliefs about themselves, they are states "assertively representing propositions" acting as mere justification makers for (second order) empirical beliefs. One might thus think that construing experience as a mere justification maker is not as much in need of special motivation as I made it out to be above (one might draw on Pryor 2005 here). But whether the state we form an introspective belief about is a headache or a (first order) belief, the characteristic difference pointed out above remains: If a state $s$ is a justification maker for a second order belief bel about $s$, bel is such that it is justified by the very object it is about. This might make good epistemological sense where the object is such that the subject has "privileged access" to it, but basic perceptual beliefs are not about experiences. They are about ordinary material objects. Thus, while it might be epistemologically fine to construe an experience as a justification maker for an introspective belief about that very experience, this does not automatically provide a model by which the experience could also be a justification maker for a (first order) basic perceptual belief. And even if we could explain how experience could have justification making powers directed simultaneously both "upwards" and "sideways", we would still need to explain why experience is so different here from belief. For even on the assumption that belief is an "immediate" justification maker for introspective belief, we do not think that puts any pressure on us to refrain from construing (first order) belief as an inferential justifier for further (first order) belief. Why would experience, if construed as a state "assertively representing propositions" - just like belief - be any different in this respect?
} 
its content.

For those of us inclined to think that one of the main arguments for construing experiences as having propositional contents in the first place is precisely their intuitive inferential integration into our belief systems, this would pretty much amount to sawing off the branch on which we are sitting. But quite independently of such motivations, it would definitely be a remarkable result in its own right if intentionalism would provide the basis for a strong case against a principle like (CP). ${ }^{23}$

\section{Content externalism to the rescue?}

In this section, I would like to take at least a quick look at the idea to use content externalism to restore a role to experiential content even on a justification maker account of experiential justification. Content externalists have repeatedly argued that the justificatory powers of perception derive from content determination. Thus, when McDowell accused Davidsonian belief systems of frictionlessly "spinning in a void" (McDowell $1994,11)$, Davidson replied by pointing to his argument that basic perceptual beliefs are by their very nature "veridical", i.e. tend to be true, because of the externalist way their contents are determined (cf. Davidson 1999). Davidson (most probably) did not think of perceptual experiences themselves as propositional attitudes, however; for him, justification started with basic perceptual beliefs. Everything up to, or "upstream from", that was just causation. ${ }^{24}$ But in his paper "Perceptual Entitlement" (2003), Tyler Burge argues that experience provides what he calls "entitlement" for belief precisely because of the externalist way experience content is determined. And Burgean entitlement is a form of positive epistemic status that would seem to squarely fall on the justification maker side of our distinction. ${ }^{25}$ According to Burge, experience content is determined

\footnotetext{
${ }^{23}$ Silins might be prepared to accept that experience is a mere justification maker. While he writes along standard intentionalist lines and thus speaks of experiences with the content that $p$ as justifying beliefs that $p$, he explicitly notes, that this is a matter of mere convenience: "For convenience I will speak of experiences as having representational contents, and as having contents that can be shared with beliefs. (...) It should be possible (although inconvenient) to adapt all formulations in the paper so as to be neutral with respect to those debates" (Silins 2014, fn. 1).

${ }^{24}$ Thus his verdict: "nothing can count as a reason for holding a belief except another belief" (Davidson $1983,141)$. Consequently, there is no defeasibility problem for Davidson, either. For more on Davidson and McDowell on perception, see Glüer 2012b.

25 "Entitlement”, Burge explains is epistemically externalist inasmuch as it is warrant that that need not be fully conceptually
} 
teleo-functionally, and in such a way that experience will be a reliable indicator of the truth of its content in the subject's "normal environment", where "[t]he normal evironment is the one by reference to which the perceptual content of the perceptual state is explained and established" (Burge 2003, 532). Thus, if experiential content for a subject $S$ is determined to be $p$ by $S$ 's relation to an environment of kind $k$, the experience not only is bound to be a reliable indicator of $p$ 's being true in $k$ environments, it will also be such that it entitles $S$ to believe that $p$ even if $S$ is not in a $k$ environment. ${ }^{26}$ This includes environments in which experience is no reliable indicator at all.

On such an account, experience would be a justification maker, not a justifier, but it would be a justification maker precisely because of its content, more precisely, because of the way its content is determined. Thus, a Burgean account of experiential justification or entitlement might allow an intentionalist to hold on to (CP), after all. It seems to me, however, that - without further argument at least - something essential is missing from the Burgean account. And the lacuna is precisely at the point where the content is deprived of its evidential or inferential powers. If this lacuna cannot be filled, that is, we have at least some reason to think that the way intentionalism must comply with (CP) is given by something like (PC).

According to Burge, reliability is essential for experiential entitlement, but only in privileged environments, environments of the content determining kind. This allows Burge to account for the "internalist" intuition that experience can provide justification for a particular belief regardless of whether we are in an "evil demon scenario" or not. And it provides the link between content determination, and a property of the experience that is immediately recognizable as epistemic: its reliability. But even if we grant the underlying content externalism, even if we grant that it is of the essence of a perceptual state that it reliably indicates the truth of its own content in an environment of the

accessible, even on reflection, to the warranted individual. The individual need not have the concepts necessary to think the propositional content that formulates the warrant. Entitlements that I shall discuss are epistemically externalist in the further sense that the warranting features include relations between the individual and an environment (Burge 2003, 504f).

\footnotetext{
${ }^{26}$ According to Burge himself, perceptual states have representational contents that are truth-conditional, but not propositional. The belief that you are (prima facie) entitled to form on the basis of an experience with such a content is what he calls "an appropriately conceptualized perceptual belief" (ibid.). Ignoring this difference, I am using ' $p$ ' for both the "conceptualized” belief content and the "unconceptualized" experience content here.
} 
content-determining kind - why would we think that this essential property of experience has epistemic significance in in other kinds of environments? More precisely, why would reliability in one kind of environment make experience provide entitlement in an environment where there is no reliability? I fail to see how, or why, content determination would speak to this. Indeed, the environments in which experience is reliable are of the same kind as the environment that determines its content. And indeed, having the content it has is essential to the experience. But why does this endow the experience with epistemic powers that it carries along to environments where it is not reliable ${ }^{27}$ As long as no further explanation is provided, what intuitive epistemological force the Burgean account has seems to derive entirely from its reliabilist element, i.e. ultimately from the idea that experiences are reliable indicators of certain conditions in our actual environment. But that much was plausible from the start - the plausibility of the indicator-idea does not depend on our account of content determination. Both content externalists and content internalists can agree on it. Moreover, even those who deny experience any content whatsoever aren't thereby committed to denying that experience is a reliable indicator. ${ }^{28}$ By itself, this idea does nothing to establish the claim that experience's possible epistemic status as a justification maker depends on its content in any way. Pending further argument, content externalism thus does not seem to rescue (CP) for the intentionalist. ${ }^{29}$

\footnotetext{
${ }^{27}$ For further discussion of Burge's suggestion, see Silins 2012.

${ }^{28}$ The epistemic disjunctivist might not have much epistemological use for the indicator-idea, construing entitlement along McDowellian lines, for instance, as conferred by states of seeing (or veridical experience in other modalities) only. But states of seeing are, of course, supremely reliable indicators.

${ }^{29}$ Schellenberg (2013) argues along lines somewhat similar to Burge's for the claim that experience provides what she calls "phenomenal evidence" for belief. According to Schellenberg, the function of experience is to single out particulars and property instances in one's environment, and having perceptual experiences is exercising perceptual capacities to do so. From this, she derives a claim according to which "good cases", i.e. cases in which the subject succeeds in experientially singling out particulars and property instances, have metaphysical (and explanatory) priority over "bad cases", i.e. cases of illusion or hallucination. This, she argues, is why an experience as of $p$ provides "phenomenal" evidence for believing that $p$-regardless of whether the experience is illusory or not, and regardless of its reliability (cf. Schellenberg 2013, 700ff; 720). Again, epistemological consequences are drawn from metaphysical claims about essential relations between experience (content) and the environment. (For Schellenberg, this involves content externalism insofar as she thinks of concepts in "capacity terms", i.e. of concept possession as consisting in the possession of certain kinds of cognitive capacities.) But here, there is no connection with reliability at all. So, how do we derive any epistemic characteristics for experience, then?

According to Schellenberg, it is rational for a subject to rely on their experiences precisely because these are the results of exercising capacities to single out particulars and property instances. And having such capacities entails that if a subject exercises these in the presence of a suitable $F$ under suitable conditions, she will in fact succeed in perceptually singling out this $F$ and its instance of $F$-ness. Thus, the metaphysics of
} 


\section{Phenomenal intentionalism}

Is there, then, no way out of the defeasibility problem for the intentionalist? No way, that is, short of abandoning (CP)? Well, as I already indicated above, I think there is one. But it requires a sacrifice of its own. It requires giving up the admittedly quite intuitive principle (EC):

(EC) An experience as of $p$ has the content that $p$.

The basic idea is to satisfy the difference requirement by construing experiences as having contents that are different from the content of the belief they provide justification for. This could presumably be done in different ways, but a natural thought is to use some kind of "appearance proposition" as the very content of the experience. More precisely, we could use propositions ascribing "appearance properties" to objects. This would allow us to remain faithful to the idea that experiences are about ordinary material objects - what would be non-standard is only that the properties experiences ascribe to such objects are not sensible properties in the traditional sense but appearance properties.

experience is supposed to explain its epistemology - but explicitly without invoking the notion of reliability:

The notion of systematic linkage in play is understood in terms of a metaphysical and explanatory primacy notion, which is not a reliabilist notion. If perceptual capacities are employed in perception, then they happen to be reliable. However, even in this case it is the primacy of the good over the bad case that gives experience its epistemic force. On the account presented, the epistemic force of perceptual experience does not depend on whatever reliability (if any) perceptual experience might have (Schellenberg 2013, 720).

Even if we grant the highly controvertible functional metaphysics, there is the very same lacuna here as in Burge's account, it seems to me. The question, simply put, is how do we get the epistemology out of the metaphysics? And given its explicit divorce from what might well seem to be the most relevant epistemic characteristic in the vicinity - the reliability of experience - the epistemological significance of the metaphysics remains even more of a mystery here.

Moreover, it is hard to see how the link could be established in a way that preserves the claimed independence from reliability. On the assumption that reliability is a mere accident and has nothing to do with the epistemic force of experience, it should remain rational to rely on experience even in the absence of reliability. This requires that it is possible to have the capacities characterised by Schellenberg without their exercises being reliable indicators of what they function to single out. And indeed, given the way Schellenberg characterises the relevant capacities, having them does not guarantee reliability. It only guarantees that there won't be many "false negatives", so to speak - false positives might nevertheless abound. As an illustration, think of Burge's example of a rabbit's representation of danger (Burge 2003, 517). It's tokenings are very unreliable as indicators of danger in precisely that way. But even though it makes a lot of sense for the rabbit to panic in reaction to each and every one of them, it would hardly be rational for creatures like us to form danger-beliefs on the basis of a rabbity-capacity to single out instances of danger. It thus looks as if there needs to be more to having perceptual capacities than Schellenberg requires if these capacities are to explain the epistemic force of experience. Moreover, it again looks likely that reliability will be highly relevant to this explanation. 
What are appearance properties - if we think they are properties of material objects? Most people think that appearances, so understood, are relational properties. Shoemaker, who was the first to propose that experience represents appearance properties, offers two main suggestions (cf. Shoemaker 1994; Shoemaker 2000). Occurrent appearance properties are properties such as that of presently causing an experience of a particular phenomenal kind $k_{p}$ in a subject $S$. Dispositional appearance properties are properties such as being disposed to cause $k_{p}$ experiences in subjects of a particular kind (under particular circumstances). Shoemakerian appearance properties thus are relations involving a "subjective" element: relations to (phenomenal kinds of) experience or sensations. ${ }^{30}$ Alternatively, appearance properties could be understood as "objective" properties - as relational properties objects have in virtue of their intrinsic properties and the objective features of the perceptual situation or perspective, for instance. ${ }^{31}$ Whether construed as subjective or objective, those who think that experience does represent what we might think of as appearance properties usually think that experiences represents both these properties and "intrinsic" sensible properties such as color or shape. ${ }^{32}$ Obviously, no such proprosal will help with the defeasibility problem. Help is only forthcoming if we allow no other properties besides appearance properties in the content of experience. ${ }^{33}$

\footnotetext{
${ }^{30}$ Sympathies with putting subjective appearance properties into the contents of experience are expressed by, among others, Egan 2006, who suggests understanding them as "centering features", Antony 2011, and myself $(2009 ; 2012)$.

${ }^{31}$ Philosophers thinking that experience represents objective, but situation-dependent properties include Harman 1990, Tye 1995, Noë 2004, Schellenberg 2007; Schellenberg 2008, and Brogaard 2010. Brogaard thinks of these properties as "centered properties". Except for Noe, who identifies what he calls "perspectival" or "P-properties" with looks, these philosophers do not usually link them to appearances, however. Relationalists such as Brewer 2011 and Genone 2014 do identify looks or appearances with certain kinds of objective, situation-dependent properties, but they do not think that experiences represent them. Rather, they join Martin 2010 in thinking that experiences do not have representational contents at all. Martin himself goes further and argues that looks aren't relational at all. According to him, looks are identical to the basic sensible properties (for some critical discussion, see Glüer 2013.

${ }^{32}$ There are two main kinds of motivation for adopting such a "dual representationalism". Shoemaker suggests that experience represents both colors and "appearance colors" in order to allow for spectrum inversion without misrepresentation while holding on to strong representationalism, i.e. the claim that experiential content determines (experiential) phenomenal character and vice versa. Most others adopt the dual representation idea in order to explain perceptual constancies in terms of experiential content. For an argument to the effect that no such dual representationalism actually can account for the full phenomenology of perceptual constancy, see Glüer forthcoming.

${ }^{33}$ Of course, other properties may play a role in the analysis of appearance properties, but that is a different story.
} 
In previous work, I have started developing such an account (Glüer 2004; 2009). According to what I would like to call "phenomenal intentionalism", visual experience has what I have called a "phenomenal" semantics: an experience as of $p$ does not have the content $p$, but has a "phenomenal" or "looks-content" $L p$ instead. ${ }^{34}$ For reasons going beyond the scope of this paper, I think appearance properties are best construed as subjectively relational, roughly but not quite along Shoemakerian lines. ${ }^{35}$ The precise nature of the appearance properties might not matter all that much to the point I am interested in here: Once we adopt a phenomenal semantics, or more generally an appearance semantics, all the natural epistemic principles set out above hold for experience. ${ }^{36}$ The justification an experience as of $p$ provides for believing $p$ can now be understood as based on the relation of probabilification that - if experience indeed is a reliable indicator of certain conditions in the experiencing subject's environment - holds between the "appearance proposition" that it looks as if $p$ and $p$. And the conditional probability of $p$ on $L p$ will be such that defeasibility is ensured; as long as appearances can be deceptive, it will remain below 1 . Whether there is such a relation will be a worldly matter - whether experience indeed is a sufficiently reliable indicator of circumstances in a subject's environment depends on how the world is. There will thus be an externalist element in the suggested account of experiential justification. Moreover, as I have explained at greater length elsewhere (Glüer 2014), experiential justification can be con-

\footnotetext{
${ }^{34}$ Antony, too, argues that the only properties "present" in our experience are appearance properties. But she thinks that their experiential presence amounts to "representation" only in "an attenuated sense" (35f). This is because she thinks of the relation between appearance properties and experiences in such a way that it is impossible for an experience to misrepresent these properties, and of representation as requiring the possibility of misrepresentation. I think that on phenomenal intentionalism, it remains possible for experience to have false contents. This will be unusual, since it requires misclassification of one's own sensations, but it strikes me as clearly possible. But even if experience with appearance content never was false, I do not see why it would be any less representational for that. Appearance contents do have (empirical) truth conditions, and they do not lose them by being the contents of "infallible" states.

${ }^{35}$ Shoemakerian appearance properties are a good start, but where he has phenomenal kinds, I think we need what could be called "functional phenomenal kinds" (I am drawing on Pagin 2000 here). The idea has been developed in more detail for color experience in Glüer 2012a.

${ }^{36}$ One of my main motivations for developing phenomenal intentionalism is accommodating both the intuitive reason providing role as well as the justificatory role of experience (Glüer 2009, Glüer 2012b, Glüer 2014). (McGrath (unp. ms) agrees that looks provide reasons (and justification) for perceptual beliefs, but thinks of looks in "fully objective" terms.)

Moreover, adopting a phenomenal semantics allows us to construe experience as a (special) kind of belief. Most importantly, it allows us to construe experience as an attitude of holding true - such an attitude is arguably required to be what I have here called an inferential justifier. Nothing short of a proposition held true provides a subject with (inferential) reasons or justification for believing another proposition. Cf. Glüer 2009, Glüer 2012b.
} 
strued as "prima facie" in the Pollockian sense: In the absence of defeaters, an experience as of $p$ provides its subject with very good reason for believing $p$ (Pollock 1974). ${ }^{37}$ And defeaters are absent as long as the subject does not have good reasons for believing any. ${ }^{38}$ Adopting a form of phenomenal intentionalism thus might provide the best way out of the defeasibility problem. Of all the principles presented above, phenomenal intentionalism needs to give up only one: (EC). It thus makes full intuitive use of the idea that if experience indeed does have representational content this content plays an essential inferential role in explaining the epistemic role of experience. This explanation has no quarrel with the probabilistic model of inferential or evidential support, a model that is both intuitive and state-of-the-art. This explanation moreover is in full accordance with our folk-epistemological practice of citing our experiences as reasons: after all, what I have to say when explaining the purchase of that ugly notebook is that it looked dark red. ${ }^{39}$

\section{References}

Antony, Louise (2011). “The Openness of Illusions”. In: Philosophical Issues 21, pp. 25-44. Brewer, Bill (1999). Perception and Reason. Oxford: Clarendon Press.

— (2006). "Perception and Content”. In: European Journal of Philosophy 14, pp. 165181.

- (2011). Perception and its Objects. Oxford: Oxford University Press.

Brogaard, Berit (2010). "Strong representationalism and centered content". In: Philosophical Studies 151, pp. 373-392.

\footnotetext{
${ }^{37}$ As Comesaña notes, externalism about the relation of evidential support is rather widespread these days (cf. Comesaña 2005). Pollock himself, however, construed the relation between experience and basic perceptual belief as a conceptual matter. While I think that goes too far, I do think that the ability to draw the right inferences from (undefeated) experience, inferences from looks red to is red, for instance, is sufficiently basic to content determination to set experience apart from, say, brute clairvoyance cases. For more on that, see Glüer 2014.

${ }^{38}$ This position of course is similar to "dogmatism" (cf. above, note 9) in embracing Pollockian prima facie justification as the model for experiential justification. As Pryor develops it, dogmatism construes experience as what I have called a mere "justification maker", not an inferential justifier, however. Given that the experiential input proposition is a looks-proposition, there is no particular anti-skeptical punch to the account of experiential justification suggested here. After all, as noted above (fn. 19), an input proposition $L p$ not only provides evidential support for $p$, but indeed for any "phenomenally equivalent" skeptical hypothesis as well, even though presumably much less of it.

${ }^{39}$ I would like to thank Juan Comesaña, James Genone, Susanna Schellenberg, and Peter Pagin for very helpful comments and discussion.
} 
Burge, Tyler (2003). “Perceptual Entitlement”. In: Philosophy and Phenomenological Research LXVII, pp. 503-548.

Byrne, Alex (2009). “Experience and Content”. In: The Philosophical Quarterly 59, pp. 429451.

Carnap, Rudolf (1950). Logical Foundations of Probability Theory. Chicago: Chicago University Press.

Cohen, Stewart (2005). "Why Basic Knowledge is Easy Knowledge”. In: Philosophy and Phenomenological Research 70, pp. 417-430.

Comesaña, Juan (2005). “We are (almost) all Externalists Now”. In: Philosophical Perspectives 19, pp. 59-76.

- (2014). "There is No Immediate Justification". In: Contemporary Debates in Epistemology, Second Edition. Ed. by Mattias Steup; John Turri; Ernest Sosa. Oxford: WileyBlackwell, pp. 222-235.

Crane, Tim (2001). Elements of Mind. Oxford: Oxford University Press.

Davidson, Donald (1983). "A Coherence Theory of Truth and Knowledge”. In: Subjective, Intersubjective, Objective. Oxford: Clarendon Press 2001, pp. 137-153.

- (1999). "Reply to John McDowell". In: The Philosophy of Donald Davidson. Ed. by Lewis Edwin Hahn. Chicago and La Salle, Ill.: Open Court, pp. 105-108.

Egan, Andy (2006). “Appearance Properties?” In: Nous 40, pp. 495-521.

Genone, James (2014). “Appearance and Illusion”. In: Mind 123, pp. 339-376.

Glüer, Kathrin (2004). “On Perceiving That”. In: Theoria 70, pp. 197-212.

- (2009). "In Defence of a Doxastic Account of Experience". In: Mind and Language 24, pp. 297-373.

- (2012a). "Colors and the Content of Color Experience". In: Croation Journal of Philosophy 12, pp. 421-437.

- (2012b). "Perception and Intermediaries". In: Donald Davidson on Truth, Meaning, and the Mental. Ed. by Gerhard Preyer. Oxford: Oxford University Press, pp. 192-213.

- (2013). “Martin on the Semantics of 'Looks'”. In: Thought 1, pp. 292-300.

- (2014). "Looks, Reasons, and Experiences". In: Does Perception Have Content? Ed. by Berit Brogaard. Oxford University Press, pp. 76-102. 
- (forthcoming). "Constancy in Variation. An Argument for Centering the Content of Experience?" In: De Se Thought and Communication. Ed. by Stefan Torre and Manuel García-Carpintero. Oxford: Oxford University Press.

Goldman, Alvin (2011). “Toward a Synthesis of Reliabilism and Evidentialism? Or: Evidentialisms's Troubles, Reliabilism's Rescue Package". In: Evidentialism and its Discontents. Ed. by Trent Doughterty. Oxford: Oxford University Press, pp. 254-280.

Harman, Gilbert (1990). “The Intrinsic Quality of Experience”. In: Philosophical Perspectives: Action Theory and Philosophy of Mind. Ed. by James Tomberlin. Vol. 4. Northridge, CA: Ridgeview, pp. 31-52.

Heck, Richard G. (2000). “Non-Conceptual Content and the 'Space of Reasons'”. In: Philosophical Review 109, pp. 483-523.

— (2007). “Are There Different Kinds of Content?” In: Contemporary Debates in the Philosophy of Mind. Ed. by Jonathan Cohen; Brian McLaughlin. Oxford: Blackwell, pp. 117138.

Martin, M. G. F. (2002). “The Transparency of Experience”. In: Mind and Language 17, pp. 376-425.

— (2010). "What's in a Look?" In: Perceiving the World. Ed. by Bence Nanay. Oxford: Oxford University Press, pp. 160-225.

McDowell, John (1982). “Criteria, Defeasibility, and Knowledge”. In: Meaning, Knowledge, and Reality. Cambridge, MA: Harvard University Press 1998, pp. 369-394.

- (1994). Mind and World. Cambridge, MA: Harvard University Press.

McDowell, John (1998). "Reply to Commentators”. In: Philosophy and Phenomenological Research 58, pp. 403-431.

- (2008). "Avoiding the Myth of the Given”. In: John McDowell: Experience, Norm, and Nature. Ed. by Jakob Lindgaard. Oxford: Wiley-Blackwell, pp. 1-14.

McGrath, Matthew (2013). “Dogmatism, Underminers and Skepticism”. In: Philosophy and Phenomenological Research 86, pp. 533-562.

- (unp. ms). "Looks and Perceptual Justification".

Noë, Alva (2004). Action in Perception. Cambridge, MA: MIT Press.

Pagin, Peter (2000). “Sensation Terms”. In: Dialectica 54, pp. 177-199. 
Pautz, Adam (2009). “What are the Contents of Experiences?” In: The Philosophical Quarterly 59, pp. 483-507.

Pollock, John (1974). Knowledge and Justification. Princeton: Princeton University Press.

Pryor, J. (2000). “The Skeptic and the Dogmatist”. In: Nous 34, pp. 517-549.

— (2005). “There is Immediate Justification”. In: Contemporary Debates in Epistemology. Ed. by M. Steup; E. Sosa. Oxford: Blackwell, 181-202ß.

Schellenberg, Susanna (2007). “Action and Self-Location in Perception”. In: Mind 116, pp. 603-631.

— (2008). "The Situation-Dependency of Perception". In: The Journal of Philosophy 105, pp. 55-84.

- (2011). "Perceptual Content Defended". In: Nous 45, pp. 714-750.

— (2013). "Experience and Evidence". In: Mind 122, 699-747ß.

Searle, John (1983). Intentionality. Cambridge: Cambridge University Press.

Shoemaker, Sidney (1994). "Phenomenal Character". In: Nous 28, pp. 21-39.

— (2000). "Introspection and Phenomenal Character". In: Philosophical Topics 28.247273.

Siegel, Susanna (2010). “Do Experiences Have Contents?” In: Perceiving the World. Ed. by Bence Nanay. Oxford: Oxford University Press, pp. 333-368.

- (2011). The Contents of Visual Experience. New York: Oxford University Press.

Siegel, Susanna and Nicholas Silins (forthcoming). “The Epistemology of Perception”. In: Oxford Handbook of Philosophy of Perception. Ed. by Mohan Matthen. Oxford.

Silins, Nicholas (2012). “Explaining Perceptual Entitlement”. In: Erkenntnis 76, pp. 243261.

— (2014). "The Agony of Defeat?" In: Philosophy and Phenomenological Research. URL: http://dx.doi.org/10.1111/phpr.12087.

Speaks, Jeff (2005). “Is There a Problem about Nonconceptual Content?” In: Philosophical Review 114, pp. 359-398.

Spectre, Levi (2009). "Knowledge Closure and Knowledge Openness. A Study of Epistemic Closure Principles". PhD thesis. Stockholm University.

Travis, Charles (2004). “The Silence of the Senses”. In: Mind 113, pp. 57-94. 
Tye, Michael (1995). “Perceptual Experience is a Many-Layered Thing”. In: Philosophical Issues 7, pp. 117-126.

White, Roger (2006). "Problems for Dogmatism”. In: Philosophical Studies 131, pp. 525557.

Williamson, Timothy (2000). Knowledge and its Limits. Oxford: Oxford University Press. Wright, Crispin (2004). "Warrant for Nothing (and Foundations for Free?)” In: Proceedings of the Aristotelian Society, Supplementary Volume 78, pp. 167-212.

— (2007). "The Perils of Dogmatism”. In: Themes from G. E. Moore: New Essays in Epistemology and Ethics. Ed. by Susana Nuccetelli and Gary Seay. Oxford: Oxford University Press, pp. 25-47. 